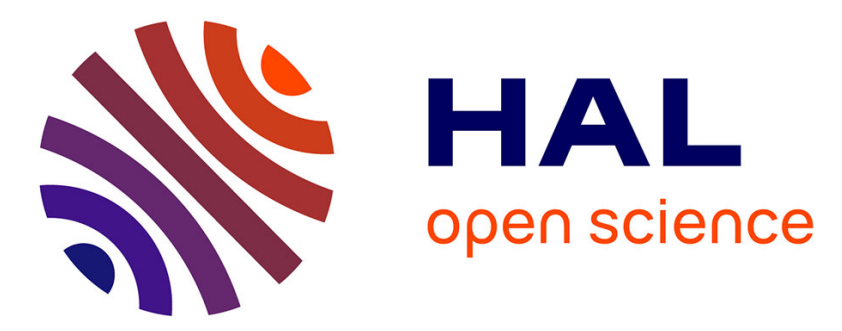

\title{
Preparation and characterization of porous alumina-based catalyst coatings in microchannels
}

Gabriele Germani, A. Stefanescu, Yves Schuurman, André C van Veen

\section{To cite this version:}

Gabriele Germani, A. Stefanescu, Yves Schuurman, André C van Veen. Preparation and characterization of porous alumina-based catalyst coatings in microchannels. Chemical Engineering Science, 2007, 62 (18-20), pp.5084-5091. 10.1016/j.ces.2007.02.034 . hal-00189096

\section{HAL Id: hal-00189096 https://hal.science/hal-00189096}

Submitted on 13 Aug 2021

HAL is a multi-disciplinary open access archive for the deposit and dissemination of scientific research documents, whether they are published or not. The documents may come from teaching and research institutions in France or abroad, or from public or private research centers.
L'archive ouverte pluridisciplinaire HAL, est destinée au dépôt et à la diffusion de documents scientifiques de niveau recherche, publiés ou non, émanant des établissements d'enseignement et de recherche français ou étrangers, des laboratoires publics ou privés.

\section{(c)(1)}

Distributed under a Creative Commons Attribution| 4.0 International License 


\title{
Preparation and characterization of porous alumina-based catalyst coatings in microchannels
}

\author{
G. Germani, A. Stefanescu, Y. Schuurman*, A.C. van Veen \\ Institut de Recherches sur la Catalyse, CNRS, 2 Avenue Albert Einstein, 69626 Villeurbanne, France
}

\begin{abstract}
Advances in the technology of micro-structured catalytic reactors depend crucially on the catalyst layer development. A detailed investigation on the influence of the different variables on the coating quality has lead to a procedure to coat commercial catalysts inside stainless steel microchannels with good adhesion and no loss of catalytic activity. A commercially available catalyst sample is directly slurry-coated inside the microchannels. These $\mu$-structured catalysts are tested for the water-gas shift reaction and compared to powder samples that underwent the same procedure. Adhesion of an alumina coating depends on both the initial particle size and the degree of macro-porosity. The latter is influenced by the nature of the binder. In the case of the commercial catalyst the particle size was difficult to control as milling was found to deteriorate its activity. Binders that can form metal complexes should be avoided in order to prevent redispersion of the active phase.
\end{abstract}

Keywords: Microstructure; Catalysis; Formulation; Rheology; Water-gas shift; Slurry coating

\section{Introduction}

Advances in the technology of microstructured catalytic reactors depend crucially on the catalyst layer development. Coatings need to be homogenous in thickness with a high surface area and an excellent adhesion as well as a good dispersion of the active phase and long-term stability. The deposition of catalysts in micro channels can be done by various means, where the most prominent way is the washcoat route followed by wet impregnation (e.g. Franz et al., 1999). Washcoats constitute an accepted class of catalysts. Another class of industrially employed catalysts are created in micro reactors via the zeolite growth method (Wan et al., 2002). Anodic oxidation is also widely used (Wiessmeier et al., 1997) to generate nano-porous oxide support layers, when aluminum reactors can be employed. Besides this, thin-film techniques such as CVD (Kestenbaum et al., 2000) and PVD, namely sputtering (Franz et al., 1999) serve for generating thin catalyst films.

\footnotetext{
* Corresponding author. Tel.: +33472445 482; fax: +33472445399.

E-mail address: yves.schuurman@ catalyse.cnrs.fr (Y. Schuurman).
}

Detailed descriptions of the procedures for the preparation of catalysts have, for instance, been given explicitly for washcoats (Pfeifer et al., 2002; Rouge et al., 2001; Zapf et al., 2003) and for zeolite growth (Wan et al., 2002). Whereas comprehensive studies exists for the deposition of alumina coatings in monoliths (Nijhuis et al., 2001) and on tubes and slabs (Valentini et al., 2001), very few comprehensive reports are devoted solely to catalyst/carrier coatings in micro channels, providing a deep insight in the subject and a detailed characterization of the coatings in term of preparation, morphology, porosity, composition. This paper evaluates the effect of a number of variables, i.e., initial particle size distribution, viscosity, nature and concentration of the binder and acidity, on the quality of the catalyst coating in the case of open reactor systems, i.e., for a precoating procedure. Two different approaches have been used: (1) An alumina coating is deposited inside the microchannels followed by an impregnation of the active phase. (2) A commercially available catalyst sample is directly slurry-coated inside the microchannels.

The study focuses on the preparation of $\mathrm{Cu} / \mathrm{Zn} / \mathrm{Al}$ catalysts because of the difficulty these formulations present with respect to properly distributing the $\mathrm{Cu}$ and $\mathrm{Zn}$. 
The obtained $\mu$-structured catalysts are tested for the water-gas shift reaction and compared to powder samples that underwent the same procedure.

\section{Experimental}

Micro-structured platelets made of stainless steel having the following dimensions: $50 \times 50 \times 1 \mathrm{~mm}$, containing 49 channels $400 \mu \mathrm{m}$ deep and $600 \mu \mathrm{m}$ wide on only one platelet side were used. The steel grade was ASTM 316Ti (DIN 1.4571). The platelets were calcined at $800{ }^{\circ} \mathrm{C}$ for $10 \mathrm{~h}$ prior to any manipulation.

For the preparation of alumina washcoats a $\gamma$-alumina powder from Alfa Aesar was used with an average particle size diameter of $3 \mu \mathrm{m}$.

Slurry coating of formulated catalysts employed a commercial LTS catalyst, C18-7, from Süd Chemie was used with a particle size of $d_{50}=28 \mu \mathrm{m}$. Its composition: $\mathrm{Al}_{2} \mathrm{O}_{3}=10-15 \%$, $\mathrm{CuO}=40-45 \%, \mathrm{ZnO}=40-50 \%$, graphite $=2-3 \%$.

Three commercially available high molecular weight polymers were selected to be used as binders:

(1) PVA (polyvinyl alcohol, 95\%, hydrolyzed, average MW= 95000 , Acros Organics).

(2) Tylose ${ }^{\circledR}$ MH 300 P2 (methylhydroxyethyl cellulose, $\mathrm{MW}=95000$, Clariant).

(3) PEG (polyethylene glycol, MW $=20000$, Avocado).

Suspensions were prepared by mixing $39.6 \mathrm{~g}$ of water with $10 \mathrm{~g}$ of catalyst and $0.4 \mathrm{~g}$ of acetic acid (AA) and $0.5-25 \mathrm{wt} \%$ of one of the above-mentioned binders. They are referred to as "binder-wt\%". A few suspensions were prepared without acetic acid ("binder-wt\%-A"). For one suspension referred to as "sol-gel", boehmite was used as a binder with the following composition: water $=39.6 \mathrm{~g}$, nitric acid $=0.4 \mathrm{~g}$, boehmite $=5.0 \mathrm{~g}$ (Disperal $180 \mathrm{~m}^{2} / \mathrm{g}, d_{50}=25 \mu \mathrm{m}$, Condea), catalyst $=5.0 \mathrm{~g}$. The original method is described in (Bravo et al., 2004), but the slurry composition used in the present work was optimized for $\gamma$-alumina.

Small amounts of suspensions PVA 2.0, Tylose ${ }^{\circledR} 0.7 \mathrm{wt} \%$, PEG $15.0 \mathrm{wt} \%$, Tylose ${ }^{\circledR} 0.7 \mathrm{wt} \%$ without AA and sol-gel were dried in a ventilated oven at $60^{\circ} \mathrm{C}$. The dried material was crushed to a powder and calcined at $300^{\circ} \mathrm{C}$ for $10 \mathrm{~h}$. A fraction of the calcined powders was pressed to form tablets and then crushed again to obtain particles. The obtained particles were sieved, and the fraction $200<\emptyset<300 \mu \mathrm{m}$ was kept for activity tests. The as-received catalyst powder was also calcined, pressed in tablets, crushed and sieved. The reactor set-up used to run the water-gas shift reaction is described in detail in (Germani and Schuurman, 2006).

Helium picnometry, mercury porosimetry and nitrogen adsorption-desorption isotherms were performed on micromeritics, Multivolume Pycnometer 1305, Poresizer 9320 and on a ASAP 2010 Analyser, respectively.

Rheological measurements in this work were performed with a visco basic plus rotational viscometer by Fungilab, with a TL5 spindle, which can read absolute viscosities in the range $30-10000 \mathrm{mPas}$, depending on rotational speed (0.3-100 RPM).

Scanning electron microscopy (SEM) was performed on a Hitachi S800 microscope, $20 \mathrm{keV}$ electrons.

Two types of adhesion tests were performed: (1) Drop test: in this test the platelets were dropped three times on a hard surface from a $50 \mathrm{~cm}$ height with the channels facing down, after which the weight loss was monitored. (2) Exposure to ultrasounds: according to a method described in the patent literature (Yasaki et al., 1993) and later used by other authors (Valentini et al., 2001), the coated platelets were immersed in petroleum ether inside a sealed beaker, and then treated in a sonicator for $30 \mathrm{~min}$. The sonicator properties are as follows: brand: Bransonic ${ }^{\circledR} 2510$, frequency: $42 \mathrm{kHz}$, RF power: $130 \mathrm{~W}$.

\section{Results}

\subsection{Slurry coating of alumina}

Initially the microstructured platelets were coated with an alumina washcoat using the different suspensions listed in Table 1.The platelets were inserted in a sample holder and the suspension was deposited in the channels with a syringe. Excess suspension was wiped away with a razor blade. The platelets were then removed from the holder, dried in still air at room temperature, and finally calcined for $10 \mathrm{~h}$ at $600{ }^{\circ} \mathrm{C}$. These suspensions showed non-Newtonian behavior and the viscosity increased exponentially with the binder concentration. The washcoats inside the microchannels are homogeneous and free of cracks. Fig. 1 shows SEM micrographs of cross-section of the coating with two different viscosities of the suspension inside the microchannel. The form and dimensions of the washcoat layers depend on the type of suspensions used, as shown in Fig. 1. These coatings were perfectly stable in both the drop test and the ultrasound test with less than $2 \%$ weight loss.

Impregnation of these coatings with a $\mathrm{Cu} / \mathrm{Zn}$ solution did lead to very inhomogeneous metal distributions, large copper crystals on the surface and very poor catalytic behavior. Therefore, another approach was tried, using suspensions prepared from commercial catalyst formulations in powder form.

\subsection{Slurry coating of commercial catalyst formulations}

Although the experience with the alumina washcoat layers showed that suspensions based on an average particle size of

Table 1

Viscosities of the alumina suspensions and typical dimensions of the alumina washcoat layers

\begin{tabular}{lrll}
\hline Suspension & Viscosity (mPas) & \multicolumn{2}{l}{ Typical dimensions } \\
\cline { 3 - 4 } & & Max & Min \\
\hline PVA-6.7 wt $\%$ & 900 & 50 & 15 \\
Tylose ${ }^{\circledR} 0.35$ wt $\%$ & 2 & 40 & 10 \\
Tylose $^{\circledR} 0.7 \mathrm{wt} \%$ & 10 & 40 & 20 \\
Tylose $^{\circledR} 1.5 \mathrm{wt} \%$ & 3200 & 40 & 25 \\
\hline
\end{tabular}



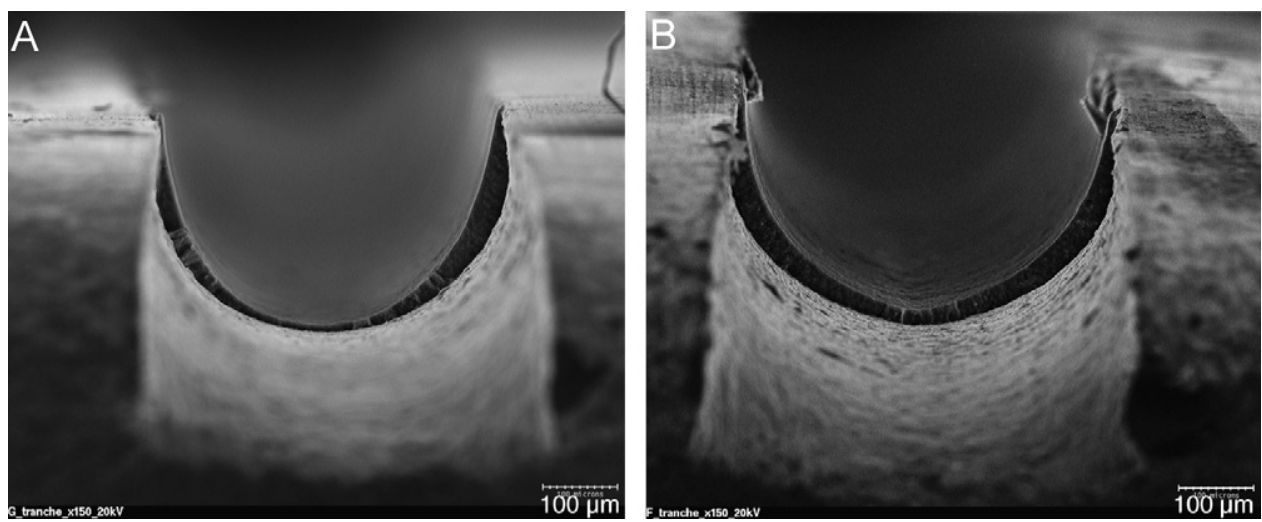

Fig. 1. SEM micrographs of the cross-section of an alumina washcoat layer inside a microchannel. (A) prepared with suspension Tylose ${ }^{\circledR} 0.35 \mathrm{wt} \%$; (B) prepared with suspension Tylose ${ }^{\circledR} 1.5 \mathrm{wt} \%$.

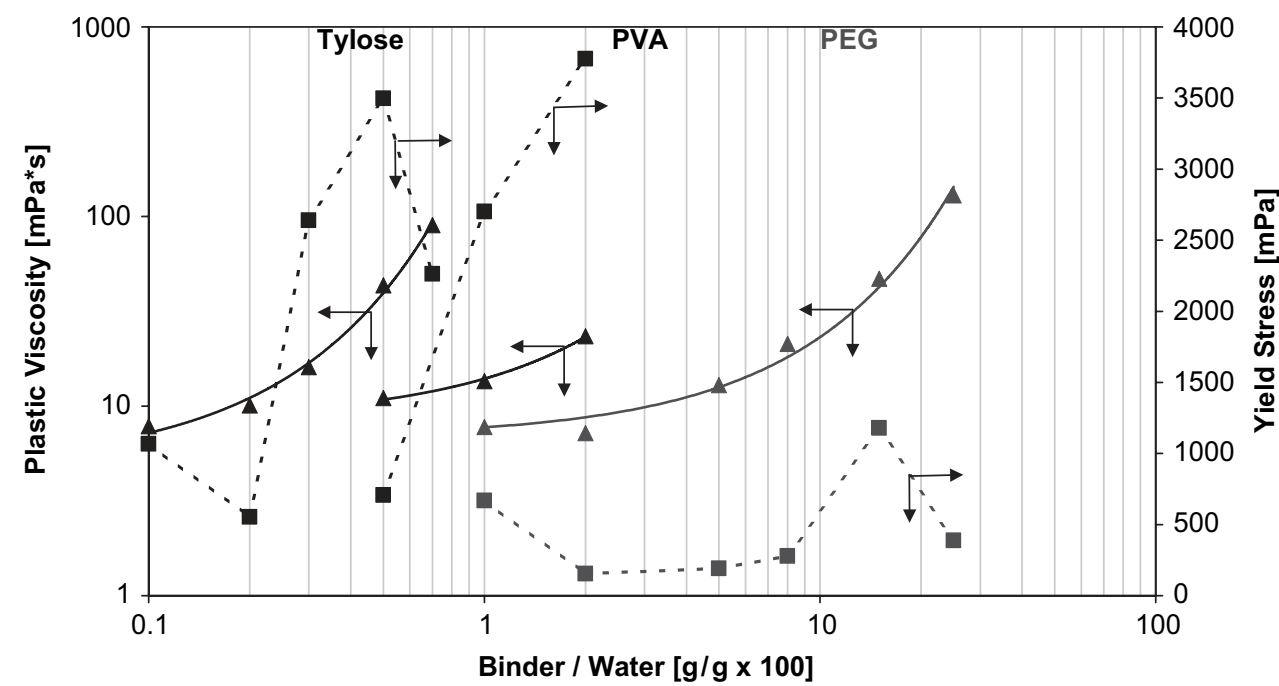

Fig. 2. Binder effect on slurry rheology for three different organic binders. The full lines represent the viscosity as a function of the amount of binder, the dashed lines yield stress at constant $\left(2 \mathrm{~s}^{-1}\right)$ shear rate.

$3 \mu \mathrm{m}$ led to good adherence, grinding down the catalyst was detrimental to its activity. Therefore it was decided to use the catalyst as received.

\subsection{Viscosity measurements}

Before preparing the catalysts coatings, a viscosity versus binder concentration curve was measured for each binder. All suspensions with the $\mathrm{Cu} / \mathrm{Zn}$ catalyst showed a non-Newtonian behavior, rather like a Bingham fluid, showing a yield stress and plastic viscosity that varied with binder content. Fig. 2 shows that for all binders, the plastic viscosity increases exponentially with binder concentration, but the amount of binder required to obtain the same thickening effect increases in the order: Tylose ${ }^{\circledR}<$ PVA $<$ PEG. Yield stress varies with binder concentration in a more complex way, but a common feature to Tylose ${ }^{\circledR}$ and PEG seems to be that it reaches a maximum and then decreases sharply. Yield stress for PEG is lower than for PVA and Tylose ${ }^{\circledR}$, even at high PEG concentrations. The differences in slurry rheology depend not only on the binder's molecular weight but also on its chemical structure. In fact, Tylose $^{\circledR}$ and PVA have the same molecular weight but Tylose ${ }^{\circledR}$ has a higher thickening effect than PVA.

In order to have approximately the same viscosity for all suspensions the following binder weight percentages were used for all other tests and experiments: PVA $2.0 \mathrm{wt} \%$, Tylose ${ }^{\circledR} 0.7 \mathrm{wt} \%$, PEG $15.0 \mathrm{wt} \%$.

\subsection{Temperature programmed decomposition (TPD)}

This analysis was done to verify the hypothesis that the organic binders were completely decomposed at $300^{\circ} \mathrm{C}$. Small amounts of the chosen suspensions were dried at room temperature, and $15 \mathrm{mg}$ of the dried solids were heated under vacuum from room temperature to $600^{\circ} \mathrm{C}$ at a rate of $20^{\circ} \mathrm{C} / \mathrm{min}$, and the gases evolved from the binders' thermal decomposition were monitored with a mass spectrometer. No carrier gas was used, thus high intensities were obtained on the mass 


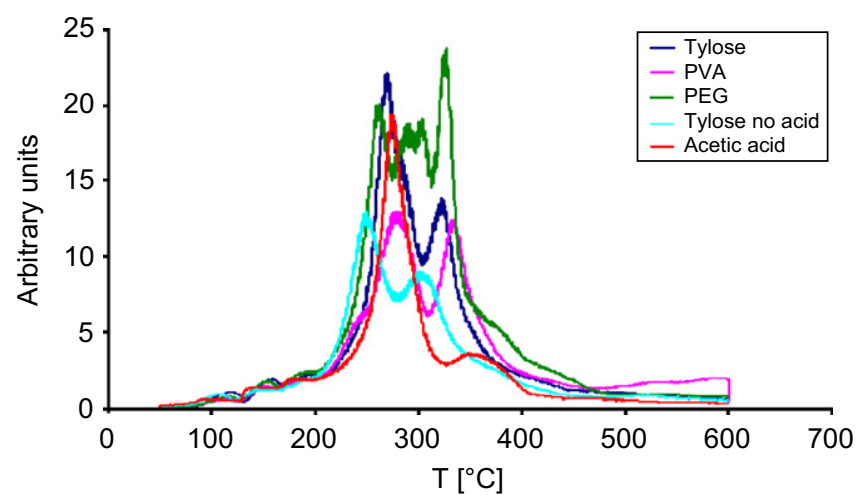

Fig. 3. TPD plots (mass 44, representative for $\mathrm{CO}_{2}$ ) for dried solids from different suspensions.

spectrometer. Masses $44\left(\mathrm{CO}_{2}\right), 28\left(\mathrm{CO}_{2}\right.$ and $\left.\mathrm{CO}\right)$ and $18\left(\mathrm{H}_{2} \mathrm{O}\right)$ were recorded. Fig. 3 shows the results. Only mass 44 is plotted, since it contains the most essential information.

From Fig. 3 the following observations are made:

- All binders evolve thermal decomposition gases, with a first peak at $250-280^{\circ} \mathrm{C}$ and a second peak at $300-350^{\circ} \mathrm{C}$;

- The decomposition of PVA seems not to be completed even at $600{ }^{\circ} \mathrm{C}$;

- Part of the evolved gases seems to come from the decomposition of acetic acid.

This last point was verified by performing the same experiment on a dried suspension that contained acetic acid but no binder (see Fig. 3).

In addition to the TPD experiments the carbon content of the powders after calcinations has been measured, by heating the samples to $1080{ }^{\circ} \mathrm{C}$ in a oxygen rich flow and analyzing the formed $\mathrm{CO}_{2}$ by acidimetric coulometry. These data showed that there was no carbon left and thus confirms the complete decomposition of the binders.

\subsection{Mercury porosimetry/picnometry-Helium picnometry}

Fifty milliliter of suspensions PVA 2.0, Tylose ${ }^{\circledR}$ 0.7, PEG 15.0 and sol-gel were prepared, together with a suspension containing acetic acid but no binder. The suspensions were poured in $110 \mathrm{~mm}$ Pyrex crystallizing dishes and dried in a ventilated oven at $60^{\circ} \mathrm{C}$. The dried slurries resulted in fragments of aggregated powder of different sizes and shapes, according to the type and amount of binder present in the slurry. These fragments were calcined $10 \mathrm{~h}$ at $300^{\circ} \mathrm{C}$ and mercury porosimetry and helium picnometry was carried out on them.

The bulk densities as measured by $\mathrm{Hg}$ picnometry as well as the skeletal densities measured by He picnometry for the different preparations are given in Table 2 . It can be seen that the fragments prepared from the slurry without any binder have the lowest bulk density. The solid prepared by the sol-gel slurry has the highest one, even if their skeletal density is the lowest one (this of course is due to the fact that $50 \%$ of their mass consists
Table 2

Bulk and skeletal densities and BET surface areas of the different suspensions

\begin{tabular}{lllc}
\hline & $\begin{array}{l}\text { Bulk density } \\
\left(\mathrm{g} / \mathrm{cm}^{3}\right)\end{array}$ & $\begin{array}{l}\text { Skeletal den- } \\
\text { sity }\left(\mathrm{g} / \mathrm{cm}^{3}\right)\end{array}$ & $\begin{array}{l}\text { BET surface } \\
\text { area }\left(\mathrm{m}^{2} / \mathrm{g}\right)\end{array}$ \\
\hline No binder & 0.88 & 5.75 & 94 \\
PVA 2.0 wt $\%$ & 0.95 & 5.60 & 67 \\
Tylose ${ }^{\circledR} 0.7 \mathrm{wt} \%$ & 1.22 & 5.37 & 68 \\
PEG 15.0 wt\% & 1.09 & 5.11 & 54 \\
Sol-gel & 1.51 & 3.75 & 128 \\
Tylose ${ }^{\circledR} 0.7 \mathrm{wt} \%$-A & n.d. & n.d. & 89 \\
\hline
\end{tabular}

of boehmite, which is lighter than copper and zinc oxides). The Tylose ${ }^{\circledR} 0.7$ sample shows a bulk density that is remarkably higher than that for the other organic binders. The cumulative volume plot of the mercury porosimetry data may help understand this result, shown in Fig. 4. It can be seen that for Tylose ${ }^{\circledR}$ $0.7 \mathrm{wt} \%$ macro-porosity starts just above $1 \mu \mathrm{m}$, whereas fragments prepared with the other organic binders show the presence of macro pores up to $10 \mu \mathrm{m}$. The use of boehmite as a binder realizes a very dense particle packing, which results in high bulk density and low intergranular porosity. The particle packing realized by the organic binders is much lower, but it is still higher for Tylose ${ }^{\circledR}$ than for PVA and PEG.

\subsection{BET surface area}

The surface area of the pure catalyst was measured by the nitrogen adsorption method and compared to that of the prepared powders. The pure catalyst underwent the same thermal treatment as the dried powders before the measurement.

It can be seen from Table 2 that PVA $2.0 \mathrm{wt} \%$ and Tylose ${ }^{\circledR}$ $0.7 \mathrm{wt} \%$ present a decrease in specific surface of $\sim 26 \mathrm{~m}^{2} / \mathrm{g}$ in comparison to the pure catalyst. Tylose ${ }^{\circledR} 0.7-\mathrm{A}$ instead shows a decrease of only $5 \mathrm{~m}^{2} / \mathrm{g}$. For PEG $15.0 \mathrm{wt} \%$ the specific surface loss amounts to $40 \mathrm{~m}^{2} / \mathrm{g}$. These data seem to indicate that small amounts of binder cause only a small surface area loss, whereas the largest loss is probably due to acetic acid; when important amounts of binder are present (PEG $15.0 \mathrm{wt} \%$ ), then the total surface area loss becomes more important. The sol-gel powder has a surface area much larger than the pure catalyst. In this case the peptized boehmite had a beneficial effect.

\subsection{Adhesion testing}

The platelets were coated with the catalyst washcoat using the different suspensions by the same method as described for the alumina coatings. They were dried in air at room temperature, and finally calcined for $10 \mathrm{~h}$ at $300^{\circ} \mathrm{C}$.

The adhesion of the catalytic coating was quantified by determining the weight loss with two testing procedures. It was found that the weight loss after exposing the sample to ultrasounds was mainly determined by the initial particle size distribution. A smaller particle size of the coating suspension leads to a better adhesion. In the case of a suspension with an average particle size of $28 \mu \mathrm{m}$, the nature of the binder has a large influence on the weight loss by the drop test (ranging from $60 \%$ to 


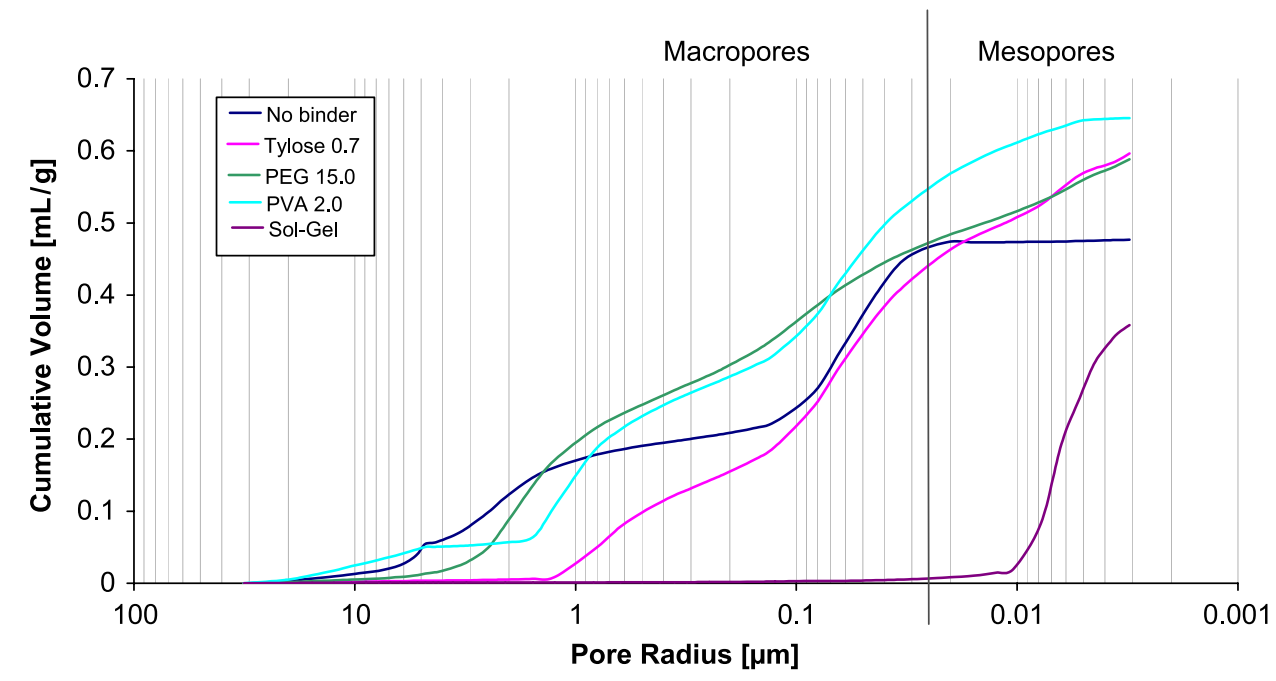

Fig. 4. Mercury porosimetry. Cumulative volume plot for the different samples.
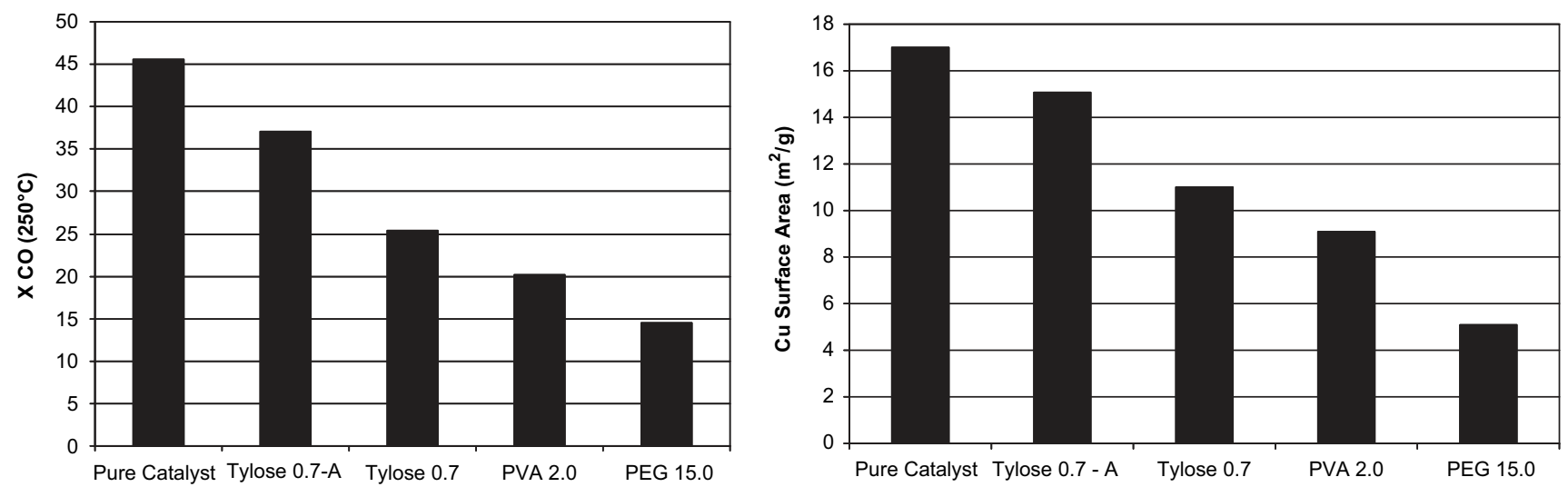

Fig. 5. Left: $\mathrm{CO}$ conversion for the different samples at $250^{\circ} \mathrm{C}, 29.0 \% \mathrm{H}_{2}, 10.0 \% \mathrm{CO}, 13.0 \% \mathrm{CO}_{2}, 25.0 \% \mathrm{H}_{2} \mathrm{O}, 23.0 \%$, Ar, $300 \mathrm{Nml} / \mathrm{min}$ total flow. Right: $\mathrm{Cu}$ surface area for coatings prepared using different binders.

$1 \%$ of weight loss). This correlates to an optimum of the macroporosity of the coatings as determined by $\mathrm{Hg}$ porosimetry.

\subsection{Catalytic activity}

The catalysts prepared with the different binders were tested for the WGS reaction between $200-250^{\circ} \mathrm{C}$. Fig. 5 shows the $\mathrm{CO}$ conversion at $250^{\circ} \mathrm{C}$ for the various binders. In order to explain the influence of the binder on the catalytic activity the $\mathrm{Cu}$ surface area was measured by $\mathrm{N}_{2} \mathrm{O}$ frontal chromatography. The results presented in Fig. 4 reveal a strong correlation between the catalytic activity and the $\mathrm{Cu}$ surface area. Moreover addition of acetic acid leads to a decreased $\mathrm{Cu}$ surface area thus suggesting that $\mathrm{Cu}$ surface area loss is due to complexation (and possibly redispersion during reduction) in the liquid phase depending on the nature of the binder. The use of Tylose ${ }^{\circledR}$ (cellulose ether) without acid leads to the best adhesion and best catalytic activity, comparable to that of the initial catalyst, presented in Fig. 6. It also leads to a uniform U- shaped washcoat with typical dimensions between $24-40 \mu \mathrm{m}$. Fig. 7 shows a SEM micrograph of the catalyst prepared with this suspension. The SEM micrograph shows parts where the washcoat has chipped off, which happened during the cutting of the platelet. SEM micrographs over the length of the channels did not show any cracks.

\section{Discussion}

Well-adhering washcoats on microstructured platelets have been obtained by deposition of a alumina layer by slurry coating a suspension containing a Tylose ${ }^{\circledR}$ binder. For many catalytic applications this forms the first step in the preparation of a structured catalysts. The active phase is subsequently added by a suitable method (impregnation, ion exchange etc.). In many cases, usually with high loadings of several active components, a homogeneous and optimal distribution of the active phase is no longer possible such as in the above case of a $\mathrm{Cu} / \mathrm{Zn}$ catalyst. In these cases it might be beneficial to slurry-coat an 
Tylose 0.7-A

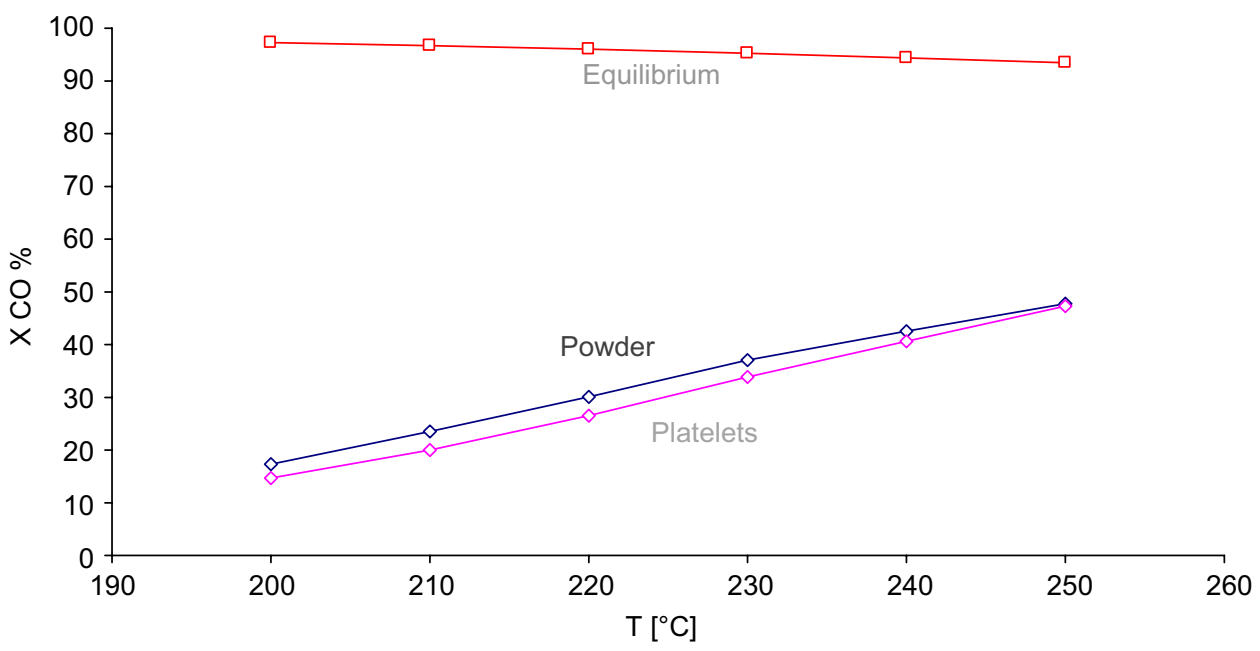

Fig. 6. Comparison between for coating prepared with Tylose ${ }^{\circledR} 0.7 \mathrm{wt} \%$ without acetic acid and the original catalyst in powder form. Conditions: $29.0 \%$ $\mathrm{H}_{2}$, $10.0 \% \mathrm{CO}, 13.0 \% \mathrm{CO}_{2}, 25.0 \% \mathrm{H}_{2} \mathrm{O}, 23.0 \%, \mathrm{Ar}, 300 \mathrm{~N} \mathrm{ml} / \mathrm{min}$ total flow.

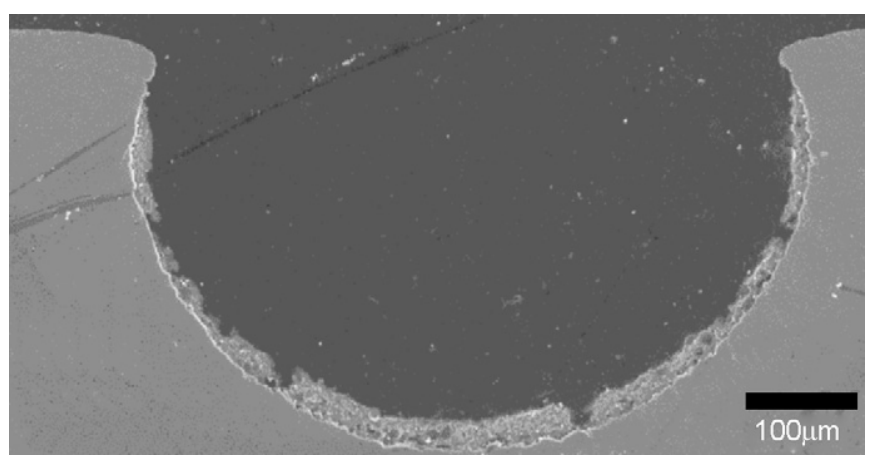

Fig. 7. SEM micrograph of the cross-section of an $\mathrm{Cu} / \mathrm{Zn}$ catalyst washcoat layer inside a microchannel, prepared with the Tylose ${ }^{\circledR} 0.7-\mathrm{A}$ suspension.

optimized catalyst. However, this leads to additional constraints to obtain good adherence. The catalyst powder might not be available with the optimal particle size and the calcination temperatures are usually much lower in order to avoid thermal sintering. These two variables have a strong effect on the catalyst adhesion (Nijhuis et al., 2001; Valentini et al., 2001). This study investigates a number of parameters, notably the nature of the binder, that effect adherence and catalytic activity of microstructured washcoat layers.

The results of the rheology analysis show that organic polymers of high molecular weight (PVA and Tylose ${ }^{\circledR}$, MW = 95000 ) cause a large increase in slurry viscosity even at low concentrations, whereas much higher concentrations are needed if the molecular weight is lower (PEG, MW $=20000$ ). This thickening effect depends not only on molecular weight, but also on the binder's chemical structure. Cellulose esters carrying methyl and hydroxyethyl groups have a higher thickening effect than polyvinyl alcohol of the same molecular weight and can therefore be used in lower concentrations. They are also easier to dissolve in water than PVA, and are therefore preferable for preparing slurries. No significant correlation has been observed between viscosity and adherence. However, the viscosity affects the form of the final washcoat. The SEM pictures in Fig. 1 indicate that suspension with higher viscosity yield more homogeneously shaped catalyst layers (U-shape) than suspensions with lower viscosity (V-shape) where most of the catalyst is located in a thick layer close to half depth of the channel whilst the top and bottom of the channel have less thick catalyst layers.

In order to rationalize the observed influence of viscosity on the coating shape, Fig. 8 displays a schematic of the drying process assumed to determine the shaping. The following assumptions found the basis for the illustration: rising viscosity enlarges the thickness of a quasi-stagnant film close to the channel wall (distance a) and the evaporation rate is not influenced by viscosity, thus the surface of the dotted triangle presenting the evaporated volume rises in both cases equivalently.

It can be deduced that in the case of the more viscous suspension, the depth penetration proceeds faster until the bottom thickness reaches approximately the same value as the quasistagnant film thickness. Beyond this point it is assumed that almost homogeneous drying, i.e., film thickness shrinking, occurs. In the case of the less viscous suspension, reaching the same bottom thickness than the thickness of the quasi-stagnant film requires longer drying and the lower viscosity should also cause that during this period part of the material in the top section of the channel slips to lower regions. Hence, the V-shape becomes favored in this way.

The behavior of the different binders upon drying of the slurry is reflected by the particle packing and the degree of shrinking of the dried powders. Particle packing was investigated in this study by means of mercury porosimetry and helium picnometry; shrinking was qualitatively evaluated through pictures of the dried slurries. The organic binders were compared to an inorganic one, namely boehmite. The results show that boehmite produces a much higher bulk density than the 

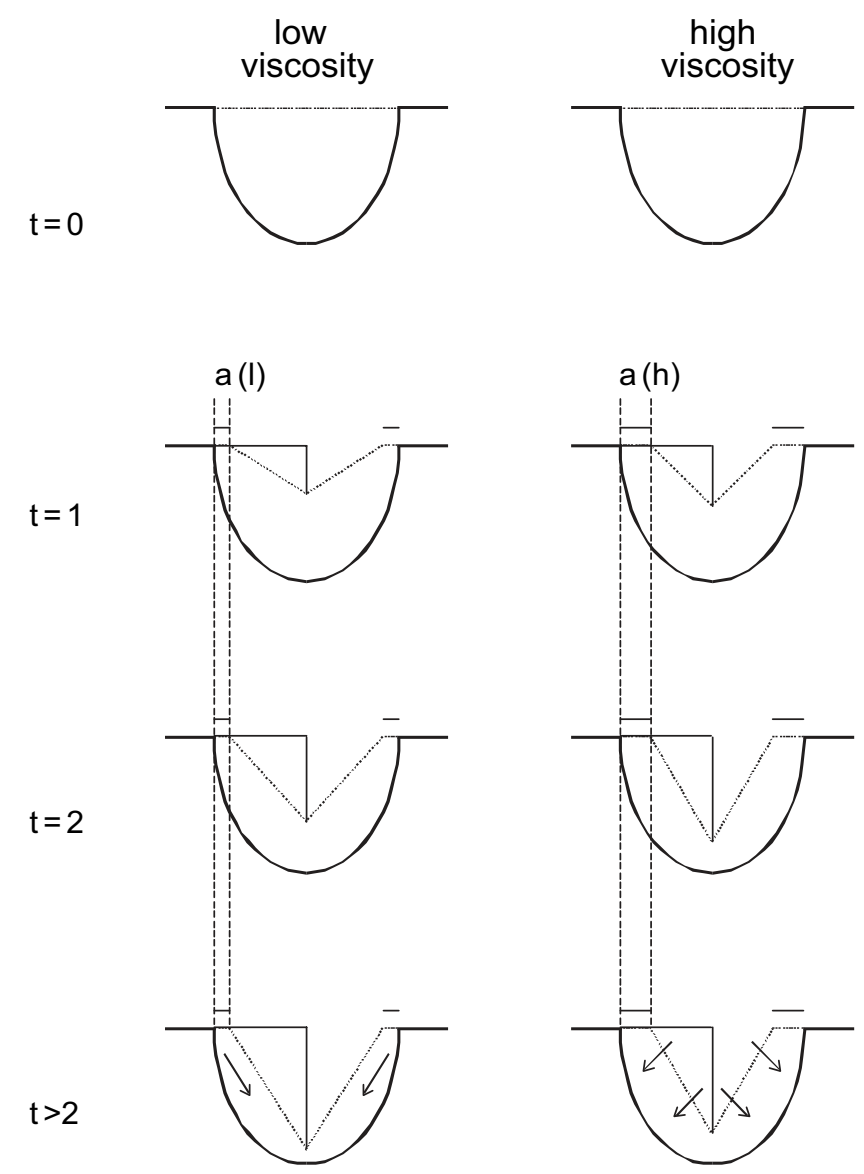

Fig. 8. Schematic of the drying process as a function of time within a microchannel at different viscosities.

organic binders, reflected by the absence of macro porosity, but also a higher degree of shrinking. PEG, on the other hand, results in low bulk density and low shrinking. In both of these extreme situations washcoat adhesion proved to be poor; in the first case because shrinking resulted in a crackled washcoat, in the second case because of insufficient cohesion of the powder grains.

PVA shows a shrinking behavior similar to boehmite, even if the bulk density is much lower. Also in this case washcoat adhesion is not satisfactory. Tylose ${ }^{\circledR}$ seems to yield the best compromise between particle packing and shrinking behavior. The washcoat is homogeneous and free of cracks for channels up to $1.0 \mathrm{~mm}$ and it passes the drop test without significant losses. Removing the acetic acid from the Tylose ${ }^{\circledR}$ slurry even improves the situation: in this case the washcoat is free of cracks. This suggests that the use of acetic acid as a dispersant is actually not necessary. Moreover, the absence of acetic acid improves the adherence of the layer, in line with the results of Valentini et al. (2001).

Regarding the diminished catalytic activity of the dried slurries, carbon determination showed that the binders were completely decomposed after calcination of the powders, so the loss of activity could not be ascribed to pore or active site blocking by organic molecules.
The loss of activity of the dried slurries was ascribed to the loss of copper surface area, as revealed by the $\mathrm{N}_{2} \mathrm{O}$ chemisorption experiments and by the activity tests. Interestingly enough, most of the $\mathrm{Cu}$ surface area loss was due to the presence of acetic acid in the suspensions. Further, it was proportional to the amount of organic binder in the slurries. It is not unreasonable to imagine that the acetic acid reacts with the smaller copper crystallites, removing part of the copper from the catalyst surface and redepositing it on the bigger particles during drying. The question remains why the loss of copper surface area is also proportional to the amount of organic binder. Thermal decomposition of PVA has been studied by Dunn et al. (1968). Two reactions can occur: (i) elimination of water and acetic acid which accounts for at least $80 \%$ of the weight loss, and (ii) depolymerization giving acetaldehyde, crotonaldehyde and higher unsaturated aldehydes, this reaction accounting for less than $20 \%$ of the total weight loss. It is then possible that, at least for PVA, the same mechanism of copper removal and redistribution takes place during calcination.

Within the limits of this work, the suspension preparation yielding the best adhesion with minimal loss of catalytic activity is therefore Tylose ${ }^{\circledR}$ 0.7-A, which contains the least amount of binder and no acid.

\section{Conclusions}

Well-adhering alumina washcoats on microstructured platelets have been obtained by deposition of an alumina layer by slurry coating a suspension containing a Tylose ${ }^{\circledR}$ binder and calcination at $600^{\circ} \mathrm{C}$. A detailed investigation on the influence of the different variables on the coating quality has lead to a procedure to coat commercial catalysts inside stainless steel microchannels with good adhesion and no loss of catalytic activity. Adhesion of an alumina coating depends on both the initial particle size and the degree of macro-porosity. The latter is influenced by the nature of the binder. The viscosity of the suspension during slurry-coating effects the shape of the washcoat. Binders that can form metal complexes should be avoided in order to prevent redispersion of the active phase.

\section{Acknowledgment}

The authors gratefully acknowledge Süd-Chemie A.G. for supplying the catalyst sample. The authors also like to thank V. Fila at the ICT Prague for the picnometry and porosimetry measurements.

\section{References}

Bravo, J., Karim, A., Conant, T., Lopez, G.P., Datye, A., 2004. Wall coating of a $\mathrm{CuO} / \mathrm{ZnO} / \mathrm{Al}_{2} \mathrm{O}_{3}$ methanol steam reforming catalyst for micro-channel reformers. Chemical Engineering Journal 101 (1-3), 113-121.

Dunn, A.S., Coley, R.L., Duncalf, B., 1968. Thermal decomposition of polyvinyl alcohol. In: Properties and Application of Polyvinyl (alcohol). Society of Chemical Industry (SCI), London, pp. 208-221.

Franz, A.J., Jensen, K.F., Schmidt, M.A., 1999. Palladium membrane microreactors. Microreaction technology: industrial prospects. Proceedings of the Third International Conference on Microreaction Technology, Frankfurt, pp. 267-276. 
Germani, G., Schuurman, Y., 2006. Water-gas shift reaction kinetics over $\mu$-structured $\mathrm{Pt} / \mathrm{CeO}_{2} / \mathrm{Al}_{2} \mathrm{O}_{3}$ catalysts. A.I.Ch.E. Journal 52 (5), 1806-1813.

Kestenbaum, H., Lange de Olivera, A., Schmidt, W., Schüth, F., Ehrfeld, W., Gebauer, K., Löwe, H., Richter, T., 2000. Silver-catalyzed oxidation of ethylene to ethylene oxide in a microreaction system. Industrial \& Engineering Chemistry Research 41 (4), 710-719.

Nijhuis, T.A., Beers, A.E.W., Vergunst, T., Hoek, I., Kapteijn, F., Moulijn, J.A., 2001. Preparation of monolithic catalysts. Catalysis Reviews 43 (4), 345-380.

Pfeifer, P., Goerke, O., Schubert, K., 2002. Washcoats and electrophoresis with coated and uncoated nanoparticles on microstructured metal foils and microstructured reactors, in: Proceedings of the Sixth International Conference on Microreaction Technology/A.I.Ch.E. Spring Meeting, New Orleans, pp. 281-287.

Rouge, A., Spoetzl, B., Gebauer, K., Schenk, R., Renken, A., 2001. Microchannel reactors for fast periodic operation: the catalytic dehydration of isopropanol. Chemical Engineering Science 56 (4), 1419-1427.
Valentini, M., Groppi, G., Cristiani, C., Levi, M., Tronconi, E., Forzatti, P., 2001. The deposition of $\gamma-\mathrm{Al}_{2} \mathrm{O}_{3}$ layers on ceramic and metallic supports for the preparation of structured catalysts. Catalysis Today 69, 307-314.

Wan, Y.S.S., Chau, J.L.H., Gavriilidis, A., Yeung, K.L., 2002. TS-1 zeolite microengineered reactors for 1-pentene epoxidation. Chemical Communications 8, 878-879.

Wiessmeier, G., Schubert, K., Hönicke, D., 1997. Monolithic microstructure reactors possessing regular mesopore systems for the successful performance of heterogeneously catalyzed reactions. In: Ehrfeld, W. (Ed.), Proceedings of the First International Conference on Microreaction Technology (IMRET 1). Springer, Berlin, pp. 20-26.

Yasaki, S., Yoshino, Y., Ihara, K., Ohkubo, K., 1993. US Patent No. 5,208,206. Zapf, R., Becker-Willinger, C., Berresheim, K., Bolz, H., Gnaser, H., Hessel, V., Kolb, G., Loeb, P., Pannwitt, A.K., Ziogas, A., 2003. Detailed characterization of various porous alumina-based catalyst coatings within microchannels and their testing for methanol steam reforming. Chemical Engineering Research and Design 81 (A7), 721-729. 